\title{
BMJ Open Efficacy and safety of intradialytic exercise in haemodialysis patients: a systematic review and meta-analysis
}

\author{
Jiang Pu, Zheng Jiang, Weihua Wu, Li Li, Liling Zhang, Ying Li, Qi Liu, Santao Ou
}

To cite: Pu J, Jiang Z, Wu W, et al. Efficacy and safety of intradialytic exercise in haemodialysis patients: a systematic review and meta-analysis. BMJ Open 2019;9:e020633. doi:10.1136/ bmjopen-2017-020633

- Prepublication history for this paper is available online. To view these files, please visit the journal online (http://dx.doi. org/10.1136/bmjopen-2017020633).

$\mathrm{JP}$ and ZJ contributed equally.

Received 14 November 2017 Revised 26 September 2018 Accepted 2 November 2018

Check for updates

(c) Author(s) (or their employer(s)) 2019. Re-use permitted under CC BY-NC. No commercial re-use. See rights and permissions. Published by BMJ.

Department of Nephrology, The Affiliated Hospital of Southwest Medical University, Luzhou, China

Correspondence to

Dr Santao 0u;

ousanta0@163.com

\section{ABSTRACT}

Objective To assess the efficacy and safety of intradialytic exercise for haemodialysis patients.

Design Systematic review and meta-analysis.

Data sources Databases, including PubMed, Embase, the Cochrane Library, China Biology Medicine and China National Knowledge Infrastructure, were screened from inception to March 2017.

Eligibility criteria Randomised controlled trials (RCTs) aimed at comparing the efficacy and safety of intradialytic exercise versus no exercise in adult patients on haemodialysis for at least 3 months. A minimum exercise programme period of 8 weeks.

Data extraction Study characteristics and study quality domains were reviewed. Studies were selected, and data extracted by two reviewers.

Data analysis The pooled risk ratios and mean differences (MDs) with 95\% Cls for dichotomous data and continuous data were calculated, respectively.

Results A total of 27 RCTs involving 1215 subjects were analysed. Compared with no exercise, intradialytic exercise increased dialysis adequacy (Kt/V) (MD 0.07, $95 \% \mathrm{Cl} 0.01$ to $0.12, \mathrm{p}=0.02$ ) and maximum volume of oxygen that the body can use during physical exertion peak oxygen consumption (MD 4.11, 95\% Cl 2.94 to 5.27, $\mathrm{p}<0.0001$ ), alleviated depression standardised mean difference $(-1.16,95 \% \mathrm{Cl}-1.86$ to $-0.45, \mathrm{p}=0.001)$ and improved physical component summary-short form-36 (SF-36) level (MD 7.72, 95\% Cl 1.93 to 13.51, $p=0.009$ ). Also, intradialytic exercise could significantly reduce systolic blood pressure (MD $-4.87,95 \% \mathrm{Cl}-9.20$ to -0.55 , $\mathrm{p}=0.03$ ) as well as diastolic blood pressure (MD -4.11 , $95 \% \mathrm{Cl}-6.50$ to $-1.72, \mathrm{p}=0.0007)$. However, intradialytic exercise could not improve mental component summarySF-36 level (MD 3.05, 95\% Cl -1.47 to 7.57, $\mathrm{p}=0.19$ ). There was no difference in the incidence of adverse events between the intradialytic exercise and control groups. Conclusions Intradialytic exercise resulted in benefits in terms of improving haemodialysis adequacy, exercise capacity, depression and quality of life for haemodialysis.

\section{INTRODUCTION}

Maintenance haemodialysis (MHD) is the major treatment option for patients with end-stage renal disease (ESRD). Due to a high prevalence of chronic kidney disease, the numbers of ESRD and MHD patients are growing rapidly. ${ }^{1}$ With progress in

\section{Strengths and limitations of this study}

This systematic review and meta-analysis provides evidence for the efficiency of intradialytic exercise in haemodialysis patients.

- Adverse events were also evaluated to judge the safety of intradialytic exercise.

- Due to the short-term follow-up in the evaluated studies, the survival rate was not studied.

- Resistance exercise and a combination of aerobic and resistance exercise were not studied.

haemodialysis technology, the life expectancy of patients on MHD has dramatically increased. However, the overall mortality and quality of life in this population are far from satisfactory. Multiple reasons contribute to unfavourable outcomes for MHD patients, among which, sedentary behaviour is associated with increased risk of mortality among dialysis patients. ${ }^{2}$ Plagued by a variety of uncomfortable symptoms, such as fatigue, pain and depression, patients on MHD are usually less physically active. Thus, it is reasonable to encourage patients on MHD to participate in, or properly increase their, physical exercise.

Intradialytic exercise is a common recommendation given to encourage patients to be physically active. ${ }^{34}$ Previous studies have suggested that intradialytic exercise is effective in reducing fatigue severity, improving sleep quality, ${ }^{5}$ enhancing exercise tolerance, ${ }^{6} 7$ improving quality of life ${ }^{8}$ and even psychological status. ${ }^{9}$ Research also indicates that intradialytic exercise can increase the efficacy of dialysis, ${ }^{10}$ subsequently alleviating inflammation, improving nutrition and bone mineral density. ${ }^{11}$ Patients typically undergo two or three haemodialysis sessions a week, with each session lasting for approximately 4 hours. Since many patients maintain bed rest during haemodialysis sessions, intradialytic exercise can be a potentially useful approach to improve their health without 
consuming extra time during the interdialytic period. Although variety in exercise during haemodialysis sessions is limited, intradialytic exercise maximises the use of the MHD time period. Additionally, intradialytic exercise has been reported to increase patient compliance. ${ }^{12}$ However, conflicting data have been reported regarding the effects of intradialytic exercise. Furthermore, patients on MHD are usually at high risk of cardiovascular events and fractures, ${ }^{13} 14$ especially arrhythmia, acute coronary syndrome, sudden cardiac death, which render them extremely vulnerable. Thus, safety concerns may arise since unexpected injury may occur during exercise.

At present, whether or not physical exercise can ensure the safety of patients as well as improve the efficacy of haemodialysis is largely unknown. Dobsak $e t a l^{7}$ reported that intradialytic exercise could significantly improve $\mathrm{Kt} / \mathrm{V}$ and exercise ability among dialysis patients, but not their quality of life. On the contrary, Hristea $e t a l^{8}$ found that intradialytic exercise did not influence patients' Kt/V or exercise ability but significantly improved their quality of life. Regarding safety issue, previous meta-analyses ${ }^{1516}$ showed that intradialytic exercise might not increase the risk of adverse events. However, it is noteworthy that among these meta-analyses, most of the included studies failed to address adverse events. Thus, their conclusions about the safety of intradialytic exercise need a second thought. This is further compounded by their contradictory findings regarding the efficacy of intradialytic exercise. Chung et al ${ }^{15}$ reported that intradialytic exercise could improve haemoglobin levels but not $6 \mathrm{~min}$ walk distance (6MWD), while Sheng et $a l^{16}$ reached quite the opposite conclusion. It seems that the risk and benefit of intradialytic exercise still remain uncertain.

In this study, we aimed to comprehensively evaluate the safety of intradialytic exercise, as well as its effects, in terms of MHD patient clinical outcomes by summarising and analysing the existing literature. Understanding the role of intradialytic exercise in MHD patients should facilitate better clinical decision-making.

\section{METHODS}

\section{Search strategy and study selection}

We conducted a comprehensive medical literature search in the following electronic databases March 2017: PubMed, Embase, Cochrane Library, China Biology Medicine and China National Knowledge Infrastructure. There were no restrictions regarding language or date of publication. The search terms on PubMed included: intradialytic, haemodialysis, hemodialysis, hemofiltration, haemofiltration, dialysis, dialyses, aerobic exercise, aerobic training, resistance exercise, resistance training, strength training, physical training, physical fitness and exercise. These terms were searched both as Medical Subject Headings terms and free-text terms. The search terms were adapted for the other databases.

Two authors (JP and ZJ) screened the retrieved literature independently in two steps. First, the two authors independently screened the titles and the abstracts and excluded literature which were obviously irrelevant. Second, the full texts of potentially eligible studies were retrieved and assessed independently by the same two review authors. They included and excluded studies according to prespecified eligibility criteria: (1) Randomised controlled trials (RCTs); (2) The subjects were adult patients on MHD for at least 3 months; (3) Patients in an intervention group receiving intradialytic exercise (including resistance exercise or/and aerobic exercise). The exercise was undertaken at least twice a week, and the whole process lasted at least 8 weeks; (4) The patients in the control group received no intradialytic exercise; (5) The studies reported on the predefined outcomes we were interested in. Our primary outcomes of interest included dialysis adequacy $(\mathrm{Kt} / \mathrm{V})$, maximum volume of oxygen that the body can use during physical exertion oxygen consumption $\left(\mathrm{VO}_{2}\right.$ peak), questionnaire on quality of life (short form-36, physical component summary (PCS) or mental component summary (MCS)), depression and adverse events; The secondary outcomes included a 6MWD, blood pressure at rest, haemoglobin $(\mathrm{Hb})$, serum phosphorus, cholesterol and albumin levels after exercise. The studies were excluded if they had (1) patients on peritoneal dialysis or with limb disabilities; (2) implementation of physical exercise anytime other than the intradialytic duration; (3) full text was irretrievable.

\section{Data extraction}

The data extracted from the included studies were as follows: (1) Publication time, first author and country; (2) Characteristics of subjects (sample size, mean age and gender, etc) (3) Detailed information on intradialytic exercise (mode, intensity, time and frequency, etc); (4) Duration of follow-up and (5) Outcomes. Any disagreement between the review authors was resolved by the support of a third review author (SO).

\section{Assessment of risk of bias}

Assessment of risk of bias was performed independently by two review authors (JP and ZJ), with disagreements resolved by discussion. Risk of bias rating for each RCT was evaluated according to the quality domains in the Cochrane risk of bias tool and the scoring system developed by Jadad et al. ${ }^{17}$ Risk of bias for each domain was rated as high (seriously weakens confidence in the results), unclear or low (unlikely to seriously alter the results).

\section{Data synthesis and statistical analysis}

Review Manager V.5.3. (Copenhagen: The Nordic Cochrane Centre, The Cochrane Collaboration, 2012) was used to generate forest plots. Dichotomous data were summarised as risk ratio (RR). Continuous data were pooled as the mean difference (MD) if the outcome measuring methods and units were identical among studies; otherwise, the standardised MD (SMD), along with $95 \%$ CIs, was used. Heterogeneity among studies was 


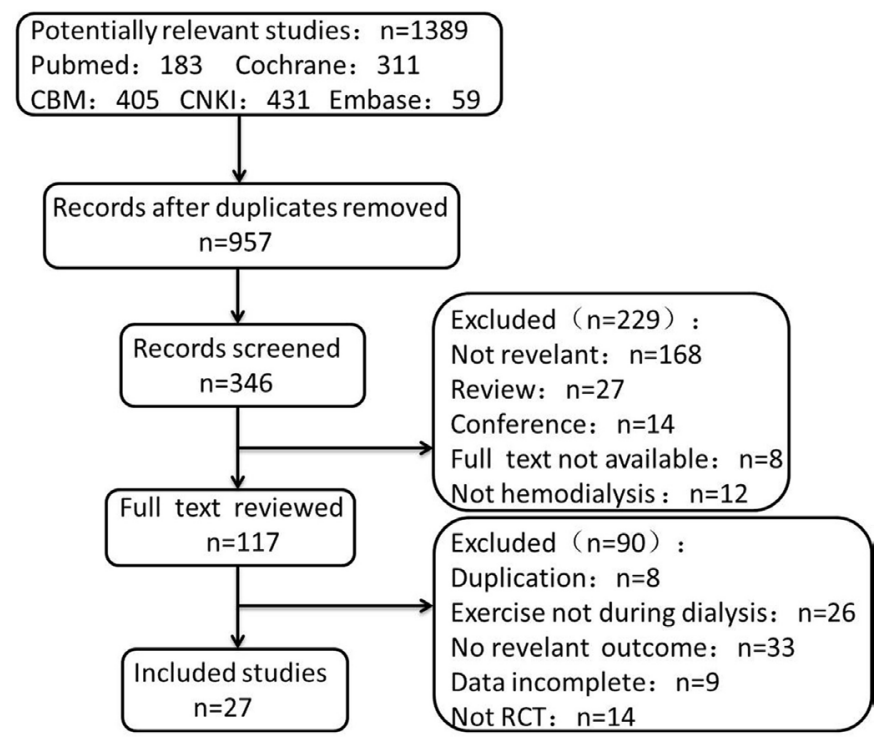

Figure 1 Flow diagram of studies considered for inclusion. CBM, China Biology Medicine; CNKI, China National Knowledge Infrastructure; RCT, randomised controlled trial.

evaluated by the $\chi^{2}$ test (assessing the $p$ value) and calculating the $\mathrm{I}^{2}$ statistic. If the $\mathrm{p}$ value was less than 0.05 and $\mathrm{I}^{2}$ exceeded $50 \%$, heterogeneity was considered substantial, and the origin of heterogeneity was analysed. For clinical heterogeneity, sensitivity analyses and subgroup analyses were performed. Alternatively, we only performed a systematic descriptive review. When heterogeneity was not substantial or obvious, the fixed effect model was used to combine the data. $\mathrm{P}<0.05$ was considered statistically significant.

\section{Patient and public involvement}

There was no patient and public involvement as this was a database research study.

\section{RESULTS}

Our initial search yielded a total of 1389 records, among which, 27 involving 1215 patients were relevant to our systematic review. ${ }^{6-12}$ 18-37 The flow diagram of studies included is shown in figure 1 . Of these 27 studies, three were three-arm study with comparison of no exercise, resistance exercise and aerobic exercise.

\section{Study characteristics and risk of bias}

Characteristics of the included studies are shown in table 1 .

A total of 27 RCTs were collected and 1215 subjects were included, among which, 723 were male and 492 were female. The average age was 53 . There were 16 studies that focused on aerobic exercise, 4 on resistance exercise and 7 on a combination of aerobic and resistance exercises. The detailed exercise protocols varied among studies. The follow-up duration ranged from 8 to 48 weeks. According to the modified Jadad scale, there were 13 high-quality articles (Jadad $\geq 4)$ and 14 low-quality articles $($ Jadad $<4)$. The Jadad scores of studies included are listed in table 1.

Among the 27 RCTs included, 13 reported the detailed randomization methods. However, only eight trials described allocation concealment in detail. Drop-out and reasons for drop-out were described in most trials, with the exception of four. In terms of blindness, due to the nature of intervention, it was impossible to blind patients or caregivers, which might introduce selection bias, performance bias and detection bias to the results. Risk of bias ratings for each trial were assessed with the Cochrane risk of bias tool. The risk of bias summary is detailed in figure 2 .

\section{Evidence from randomised trials \\ Primary outcomes \\ Dialysis adequacy and VO peak}

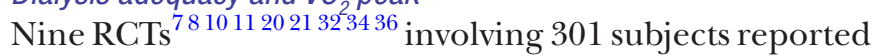
changes in $\mathrm{Kt} / \mathrm{V}$, the measure of dialysis adequacy. Within this cohort, 153 patients participated in intradialytic exercise, while 148 patients in the control groups did not. No obvious heterogeneity was found $\left(\mathrm{I}^{2}=16 \%, \mathrm{p}=0.29\right)$. The analysis of data in the fixed effect model showed that intradialytic exercise could improve Kt/V (MD 0.07, $95 \%$ CI 0.01 to $0.12, \mathrm{p}=0.02$; figure $3 \mathrm{~A}$ ). The $\mathrm{VO}_{2}$ peak (metabolic equivalents (METs), equivalent to $3.5 \mathrm{~mL} /$ $\mathrm{kg} / \mathrm{min}$ ) was measured in nine RCTs. ${ }^{6} 912202427303233$ Among the 400 enrolled patients, 205 were assigned into the intradialytic exercise groups and 195 into the control groups. Heterogeneity was also not obvious $\left(\mathrm{I}^{2}=43 \%\right.$, $\mathrm{p}=0.07$ ). Compared with control subjects, the $\mathrm{VO}_{2}$ peak in patients performing intradialytic exercise increased significantly (MD 4.11, 95\% CI 2.94 to 5.27, p<0.0001; figure $3 \mathrm{~B}$ ).

\section{Depression and quality of life}

Four RCTs ${ }^{62029}$ involving 195 patients reported on the assessment of depression levels at the baseline and endpoint. Within, 111 patients participated in intradialytic exercise, while 84 served as controls. Heterogeneity was found to be significant $\left(I^{2}=77 \%, p=0.005\right)$. The random-effects model was used to combine the data. The results showed that intradialytic exercise was able to lower the depression level (SMD -1.16, 95\% CI -1.86 to -0.45 ; figure $4 \mathrm{~A}$ ). Two aspects of quality of life, PCS and MCS, were measured within the studies. A total of 10 trials $^{7-9} 19222326293134$ that reported PCS changes were screened out. These studies involved 320 patients, 166 in the intradialytic exercise groups and 154 in the control groups. Heterogeneity was significant $\left(\mathrm{I}^{2}=77 \%\right.$, $\mathrm{p}<0.0001)$. Improved PCS was observed in the intradialytic exercise group (MD 7.72, 95\% CI 1.93 to 13.51, $\mathrm{p}=0.009$; figure 4B). However, no significant improvement in MCS from intradialytic exercise could be discerned (MD 3.05, $95 \% \mathrm{CI}-1.47$ to $7.57, \mathrm{p}=0.19$; figure $4 \mathrm{C}$ ) by analysing eight eligible RCTs. ${ }^{7-9} 2223262934$ Additionally, significant heterogeneity was also found in this comparison test $\left(\mathrm{I}^{2}=53 \%, \mathrm{p}=0.04\right)$. 


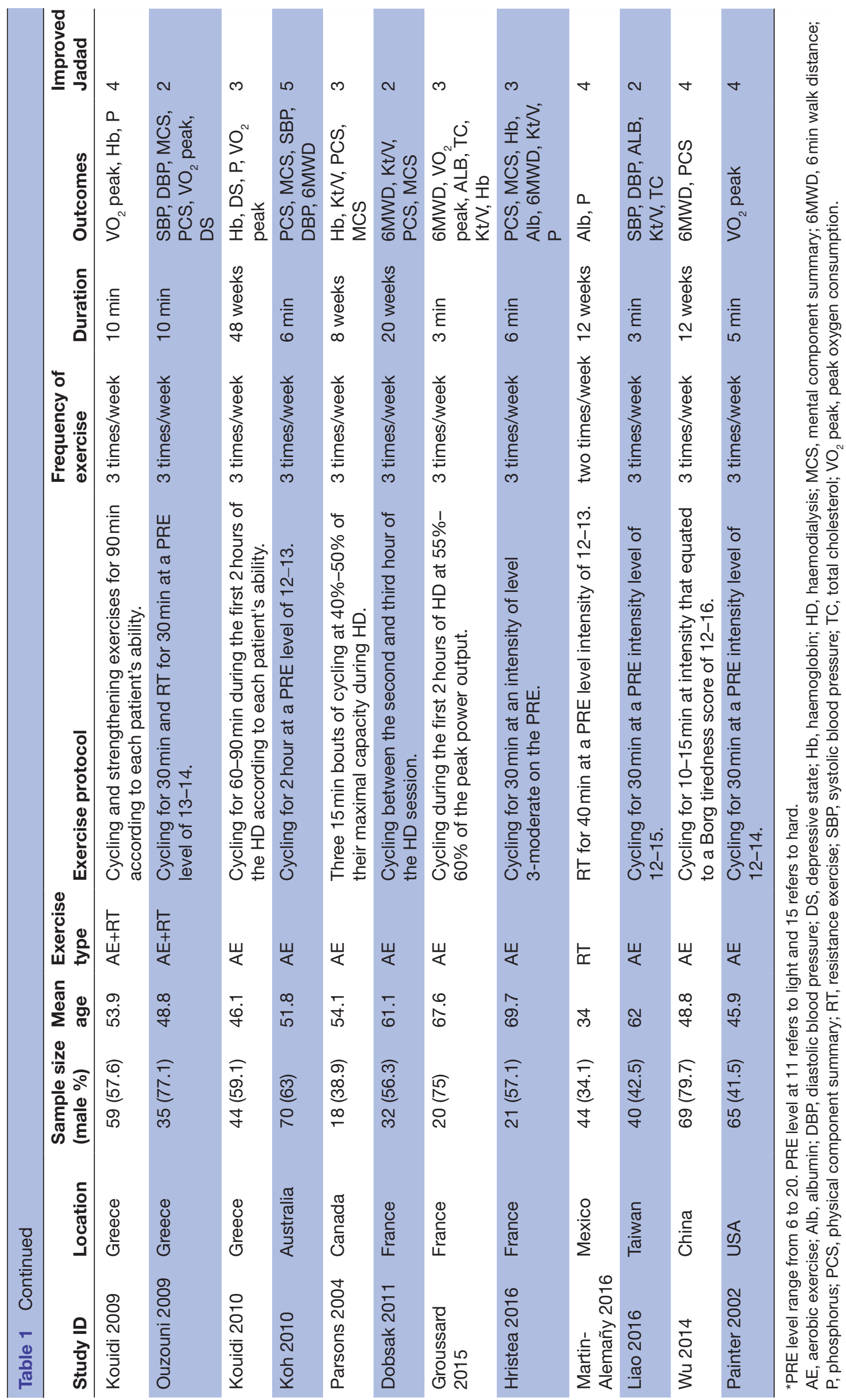


Random sequence generation (selection bias)

Allocation concealment (selection bias)

Blinding of participants and personnel (performance bias)

Blinding of outcome assessment (detection bias) Incomplete outcome data (attrition bias)

Selective reporting (reporting bias)

Other bias
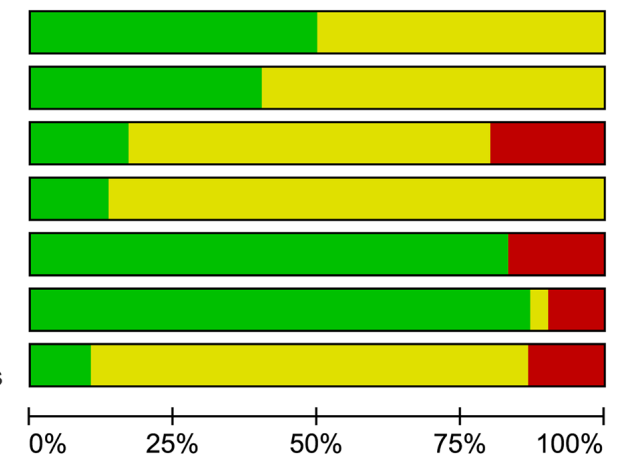

$\square$ Low risk of bias

Unclear risk of bias

High risk of bias

Figure 2 Risk of bias summary.

\section{Adverse events}

Only two studies ${ }^{28}{ }^{30}$ reported adverse events related to intradialytic exercise. Thirteen RCTs claimed that no adverse events were observed, while 12 did not mention adverse events. Two cases of hypotension (one in the intradialytic exercise group and the other in the control group) were reported in one study. Exercise-related limb pain and minor injury were found in four cases. The prevalence of adverse events between the intradialytic exercise groups and control groups was not different: RR 4.5, $95 \%$ CI 0.55 to $36.89, \mathrm{p}=0.16$ (figure 5 ).
Secondary outcomes

Twelve RCTs ${ }^{6} 81820212728$ 32-34 3637 reported comparisons in $\mathrm{Hb}(\mathrm{g} / \mathrm{L})$ levels between patients who did and did not undertake intradialytic exercise. No significant heterogeneity was found in the enrolled 459 patients (236 in the exercise groups and 223 in the control groups) $\left(\mathrm{I}^{2}=0 \%\right.$, $\mathrm{p}=0.63$ ). Intradialytic exercise was incapable of improving $\mathrm{Hb}$ levels within the fixed effect model (MD 0.01, 95\% CI -0.13 to 0.16 ; figure $6 \mathrm{~A}$ ). In terms of albumin levels, no positive effect of intradialytic exercise on albumin levels was found (SMD $0.01,95 \% \mathrm{CI}-0.29$ to $0.31, \mathrm{p}=0.95$;

\begin{tabular}{|c|c|c|c|c|c|}
\hline \multirow[b]{2}{*}{ Study or Subgroup } & \multicolumn{3}{|c|}{ Exercise } & \multicolumn{2}{|c|}{ Control } \\
\hline & Mean & SD & Total & Mean & SD \\
\hline Afshar 2010 (a) & 1 & 0.33 & 7 & 1.1 & 0.25 \\
\hline Afshar 2010 (b) & 1.12 & 0.3 & 7 & 1.1 & 0.25 \\
\hline Dobsak 2011 & 1.64 & 0.3 & 11 & 1.33 & 0.31 \\
\hline Groussard 2015 & 1.42 & 0.283 & 8 & 1.32 & 0.348 \\
\hline Hristea 2016 & 1.97 & 0.52 & 7 & 1.73 & 0.4 \\
\hline Liao 2016 & 1.52 & 0.26 & 20 & 1.52 & 0.23 \\
\hline Mohseni 2013 & 1.2 & 0.4 & 23 & 0.95 & 0.2 \\
\hline Parsons 2004 & 1.8 & 0.3 & 6 & 1.71 & 0.23 \\
\hline Reboredo 2010 & 2 & 0.8 & 11 & 1.8 & 0.7 \\
\hline van Vilsteren 2004 & 1.26 & 0.2 & 53 & 1.23 & 0.2 \\
\hline Total $(95 \% \mathrm{Cl})$ & & & 153 & & \\
\hline $\begin{array}{l}\text { Heterogeneity: } \mathrm{Chi}^{2} \\
\text { Test for overall effe }\end{array}$ & & $(P$ & & & \\
\hline
\end{tabular}

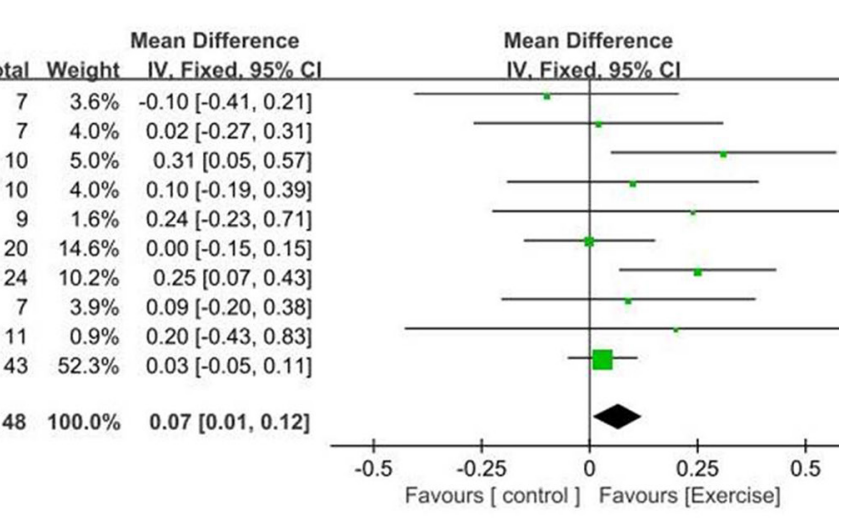

\section{(B)VO2peak}

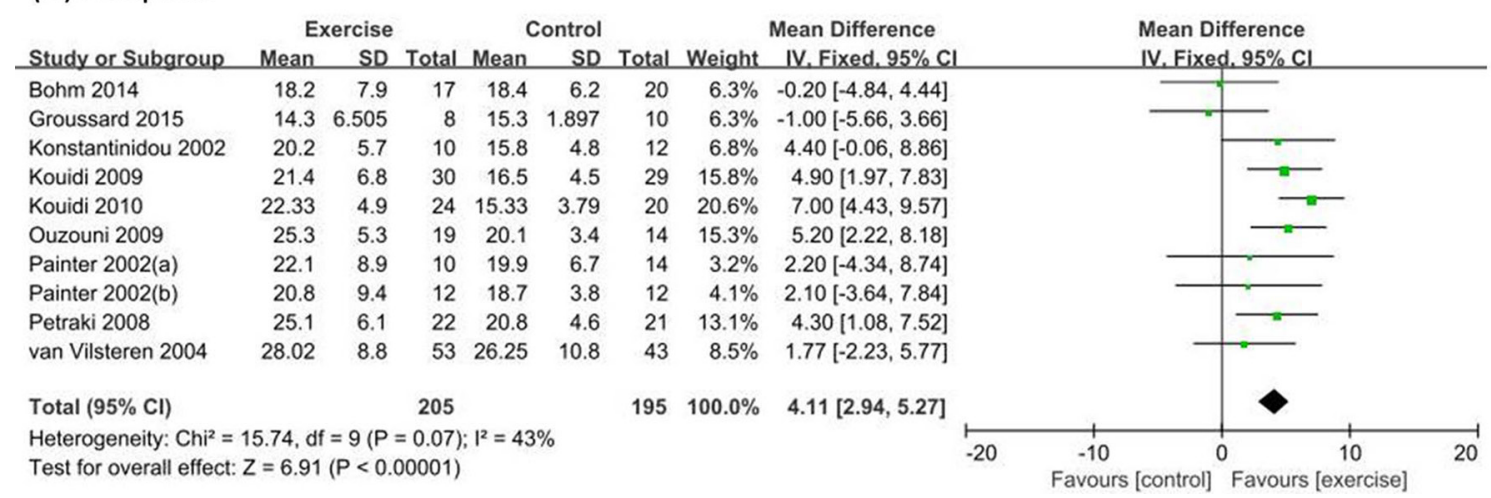

Figure 3 Forest plot: effect of intradialytic exercise on $\mathrm{Kt} / \mathrm{V}$ and $\mathrm{VO}_{2}$ peak. $\mathrm{VO}_{2}$ peak, peak oxygen consumption. 
(A)Depression

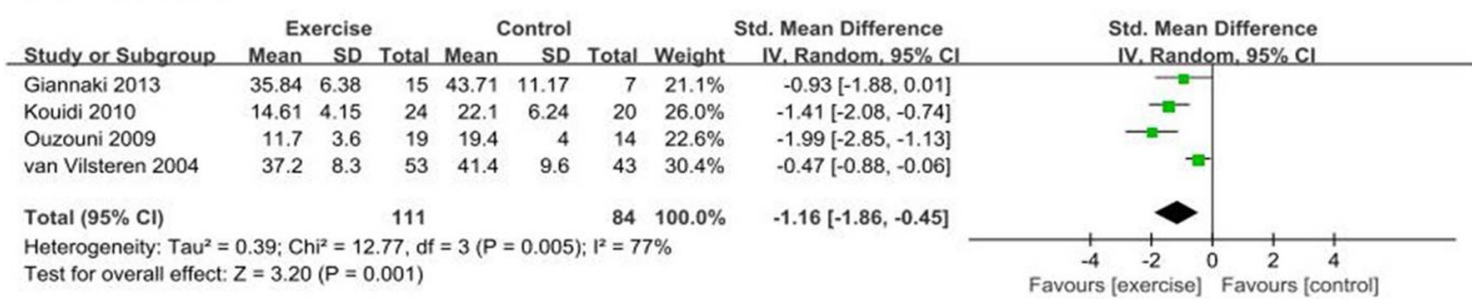

(B)PCS

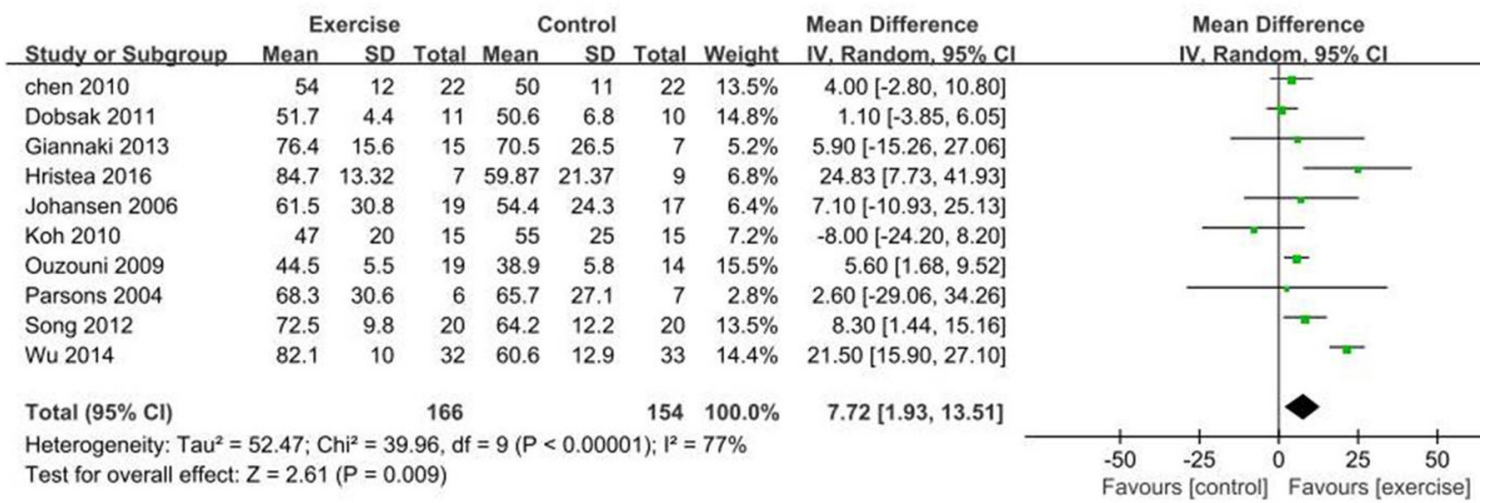

(C)MCS

\begin{tabular}{|c|c|c|c|c|c|c|c|c|c|c|}
\hline \multirow[b]{2}{*}{ Study or Subgroup } & \multicolumn{3}{|c|}{ Exercise } & \multicolumn{3}{|c|}{ Control } & \multirow{2}{*}{\multicolumn{2}{|c|}{$\begin{array}{cl} & \text { Mean Difference } \\
\text { Weight IV. Random, } 95 \% \mathrm{CI}\end{array}$}} & \multirow{2}{*}{$\begin{array}{l}\text { Mean Difference } \\
\text { IV. Random, } 95 \% \mathrm{Cl}\end{array}$} & \\
\hline & Mean & SD & Total & Mean & SD & Total & & & & \\
\hline chen 2010 & 37 & 9 & 22 & 38 & 9 & 22 & $20.4 \%$ & $-1.00[-6.32,4.32]$ & & \\
\hline Dobsak 2011 & 59.5 & 5.5 & 11 & 59.3 & 5.6 & 10 & $21.6 \%$ & $0.20[-4.56,4.96]$ & & \\
\hline Giannaki 2013 & 70.4 & 18.7 & 15 & 65 & 21.9 & 7 & $4.8 \%$ & $5.40[-13.38,24.18]$ & & \\
\hline Hristea 2016 & 74.3 & 10.61 & 7 & 52.07 & 16.11 & 9 & $8.4 \%$ & $22.23[9.09,35.37]$ & & \\
\hline Koh 2010 & 58 & 20 & 15 & 64 & 25 & 15 & $6.1 \%$ & $-6.00[-22.20,10.20]$ & & \\
\hline Ouzouni 2009 & 41.8 & 10 & 19 & 40.1 & 6.8 & 14 & $19.5 \%$ & $1.70[-4.04,7.44]$ & & \\
\hline Parsons 2004 & 80.7 & 19.8 & 6 & 84.3 & 16.9 & 7 & $4.3 \%$ & $-3.60[-23.79,16.59]$ & & \\
\hline Song 2012 & 69.4 & 13.7 & 20 & 60.8 & 12.4 & 20 & $14.9 \%$ & $8.60[0.50,16.70]$ & & \\
\hline Total $(95 \% \mathrm{CI})$ & & & 115 & & & 104 & $100.0 \%$ & $3.05[-1.47,7.57]$ & & \\
\hline \multicolumn{9}{|c|}{$\begin{array}{l}\text { Heterogeneity: } \mathrm{Tau}^{2}=18.71 ; \mathrm{Chi}^{2}=14.80, \mathrm{df}=7(P=0.04) ; \mathrm{I}^{2}=53 \% \\
\text { Test for overall effect: } Z=1.32(P=0.19)\end{array}$} & 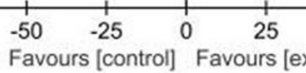 & $\begin{array}{c}50 \\
\text { rcise] }\end{array}$ \\
\hline
\end{tabular}

Figure 4 Forest plot: effect of intradialytic exercise on depression, PCS and MCS. MCS, mental component summary; PCS, physical component summary.

figure 6B) by analysis of the combined data from seven RCTs involving 175 patients. ${ }^{8} 112125323536$ No significant heterogeneity was found $\left(\mathrm{I}^{2}=0 \%, \mathrm{p}=0.88\right)$.

Eight trials ${ }^{68182125273537}$ reported data on serum phosphorus and six ${ }^{112025263236}$ reported on blood cholesterol levels. Heterogeneities were not significant in these two comparisons $\left(\mathrm{I}^{2}=27 \%, \mathrm{p}=0.21\right.$ and $\mathrm{I}^{2}=0 \%, \mathrm{p}=0.7$, respectively). Data analyses showed that intradialytic exercise could neither lower cholesterol levels (SMD -0.13 , $95 \%$ CI -0.39 to $0.13, \mathrm{p}=0.33$; figure $6 \mathrm{C}$ ) nor decrease serum inorganic phosphorus levels (SMD -0.03, 95\% CI -0.26 to 0.21 ; figure $6 \mathrm{D})$.

Seven trials ${ }^{9} 112023252833$ compared blood pressure differences between patients who did and did not undertake intradialytic exercise. A combined analysis of 287 patients revealed that intradialytic exercise could significantly reduce systolic blood pressure (SBP) (MD $-4.87 \mathrm{~mm} \mathrm{Hg}, 95 \% \mathrm{CI}-9.20$ to $-0.55, \mathrm{p}=0.03$ ) as well as diastolic blood pressure (DBP) ( $\mathrm{MD}-4.11 \mathrm{~mm}$ $\mathrm{Hg}, 95 \% \mathrm{CI}-6.50$ to $-1.72, \mathrm{p}=0.0007)$. Heterogeneities

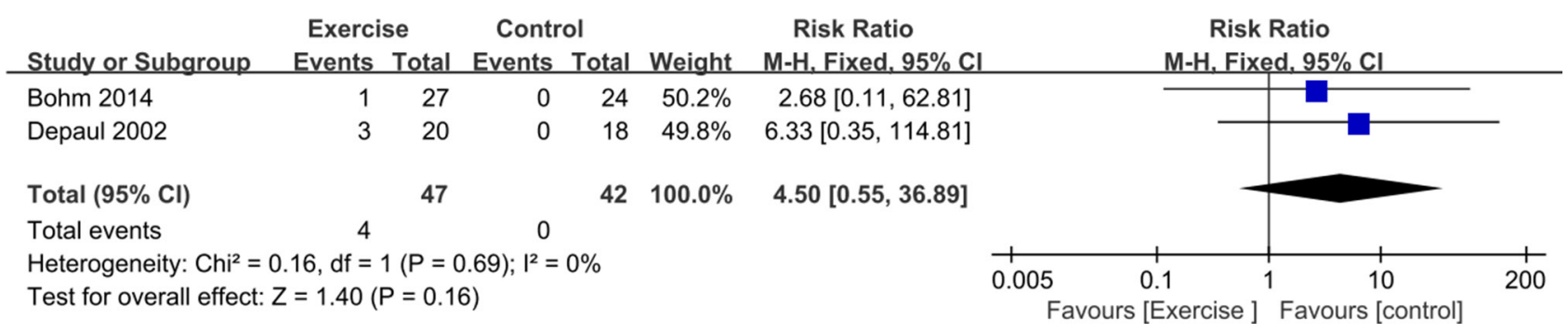

Figure 5 Forest plot of musculoskeletal complications. 
(A) $\mathrm{Hb}$

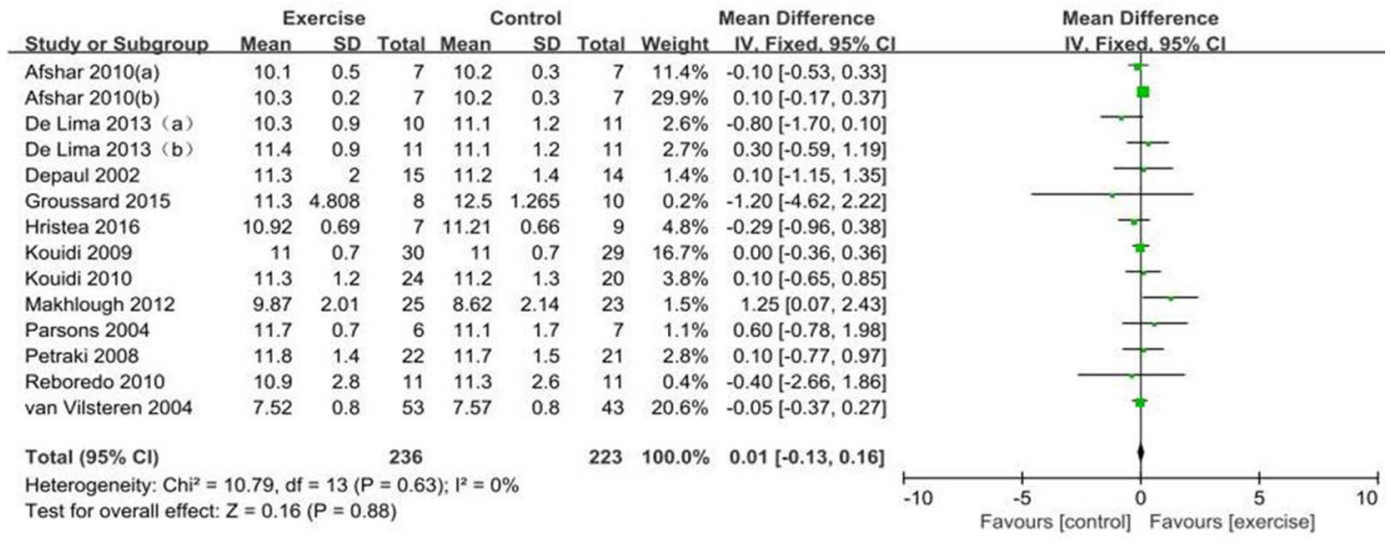

(B)Alb

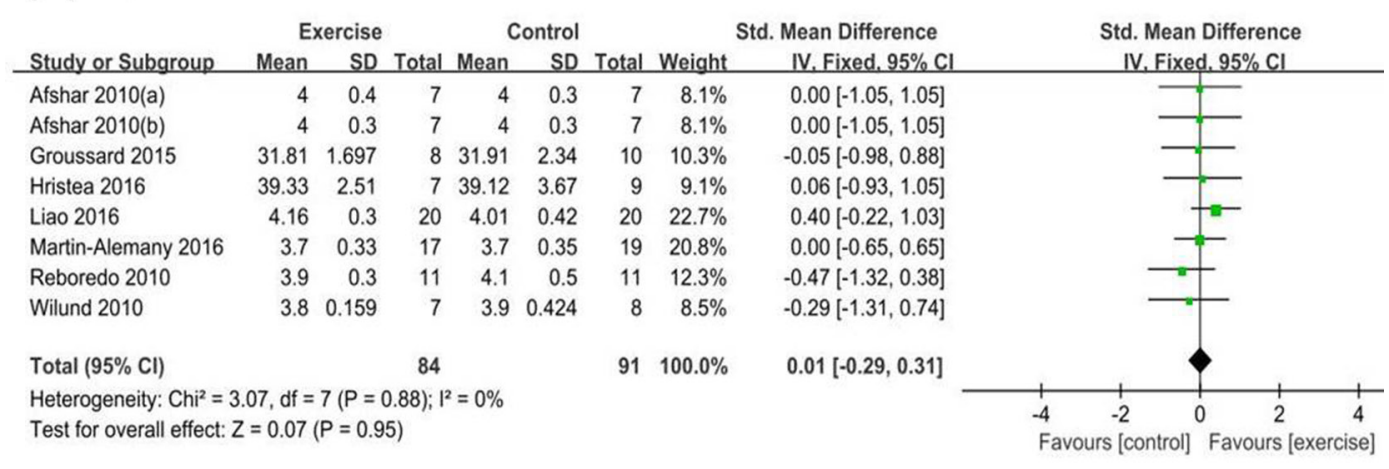

\section{(C)Cholesterol}

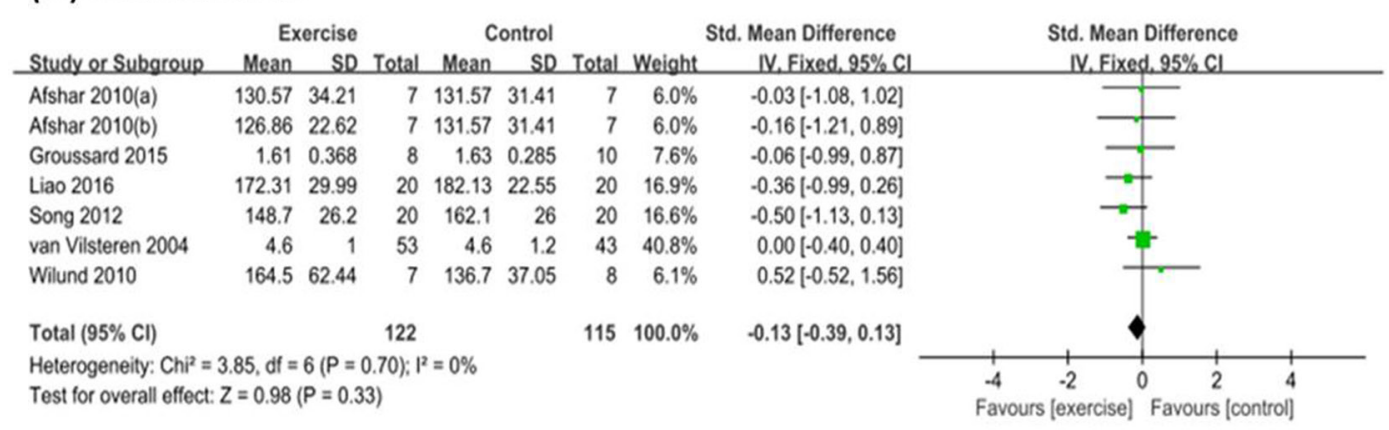

\section{(D)Phosphorus}

\begin{tabular}{|c|c|c|c|c|c|c|c|c|c|}
\hline \multirow[b]{2}{*}{ Study or Subgroup } & \multicolumn{3}{|c|}{ Exercise } & \multicolumn{2}{|c|}{ Control } & \multicolumn{3}{|c|}{ Std. Mean Difference } & \multirow{2}{*}{$\begin{array}{c}\text { Std. Mean Difference } \\
\text { IV. Fixed. } 95 \% \mathrm{Cl}\end{array}$} \\
\hline & Mean & SD & Total & Mean & SD & Total & Weight & IV. Fixed. $95 \% \mathrm{Cl}$ & \\
\hline De Lima 2013 (a) & 5.4 & 1.7 & 10 & 5.6 & 0.9 & 11 & $7.6 \%$ & $-0.14[-1.00,0.71]$ & - \\
\hline De Lima 2013 (b) & 6.6 & 1.6 & 11 & 5.6 & 0.9 & 11 & $7.4 \%$ & $0.74[-0.13,1.61]$ & \\
\hline Hristea 2016 & 1.32 & 0.42 & 7 & 1.59 & 0.42 & 9 & $5.4 \%$ & $-0.61[-1.62,0.41]$ & \\
\hline Kouidi 2009 & 6.2 & 1.1 & 30 & 6.1 & 0.8 & 29 & $21.4 \%$ & $0.10[-0.41,0.61]$ & - \\
\hline Kouidi 2010 & 6.6 & 1.7 & 24 & 6.5 & 1.6 & 20 & $15.8 \%$ & $0.06[-0.53,0.65]$ & \\
\hline Makhlough 2012 & 5.83 & 2.37 & 25 & 7.08 & 2.07 & 23 & $16.7 \%$ & $-0.55[-1.13,0.03]$ & \\
\hline Martin-Alemany 2016 & 6.4 & 2 & 17 & 5.7 & 1.9 & 19 & $12.8 \%$ & $0.35[-0.31,1.01]$ & \\
\hline Reboredo 2010 & 4.9 & 1.7 & 11 & 5.9 & 1.9 & 11 & $7.7 \%$ & $-0.53[-1.39,0.32]$ & $\gamma$ \\
\hline Wilund 2010 & 6.5 & 2.011 & 7 & 5.9 & 1.414 & 8 & $5.3 \%$ & $0.33[-0.69,1.35]$ & \\
\hline Total $(95 \% \mathrm{Cl})$ & & & 142 & & & 141 & $100.0 \%$ & $-0.03[-0.26,0.21]$ & 8 \\
\hline \multicolumn{5}{|c|}{ Heterogeneity: $\mathrm{Ch}^{2}=10.88, d f=8(P=0.21) ; I^{2}=27 \%$} & Test for overall effect: $Z=0.23(P=0.82)$ & & & & $\begin{array}{ccc}-2 & 0 & 2 \\
\text { s [exercise] } & \text { Favours }\end{array}$ \\
\hline
\end{tabular}

Figure 6 Forest plot: effect of intradialytic exercise on $\mathrm{Hb}$, Alb, cholesterol and phosphorus. Alb, albumin; Hb, haemoglobin.

were not significant in these two comparisons $\left(\mathrm{I}^{2}=4 \%\right.$, $\mathrm{p}=0.39$ and $\mathrm{I}^{2}=35 \%, \mathrm{p}=0.16$, respectively; figure $\left.7 \mathrm{~A}, \mathrm{~B}\right)$. For assessment of physical performance, seven studies with 6MWD measurements ${ }^{6} 72328$ 30-32 were screened out. Due to the absence of significant heterogeneity $\left(\mathrm{I}^{2}=0 \%\right.$, $\mathrm{p}=0.78)$, the fixed effect model was used for data analysis, 
(A)SBP

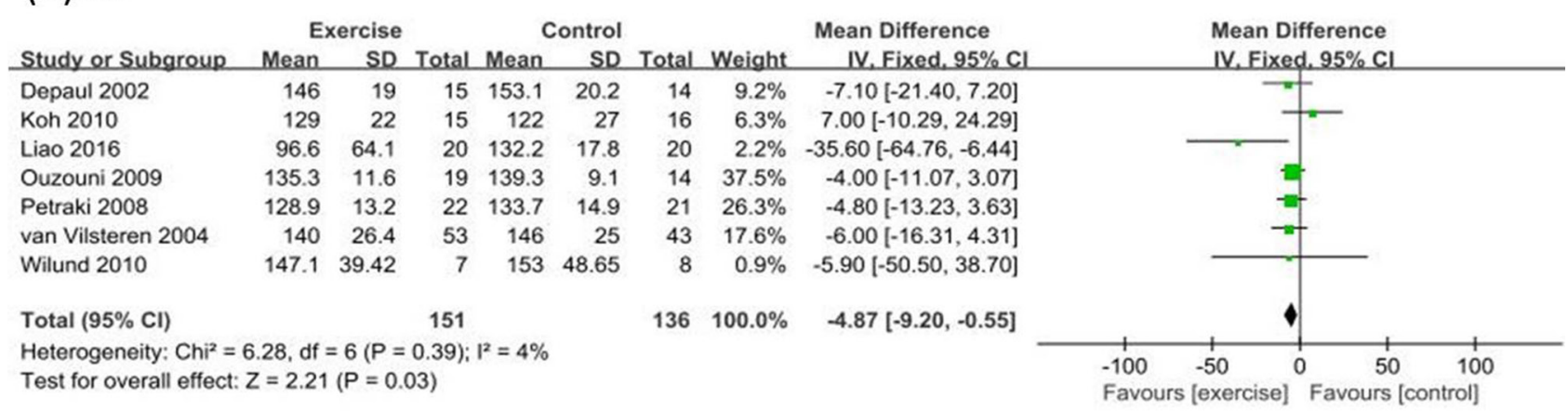

\section{(B)DBP}

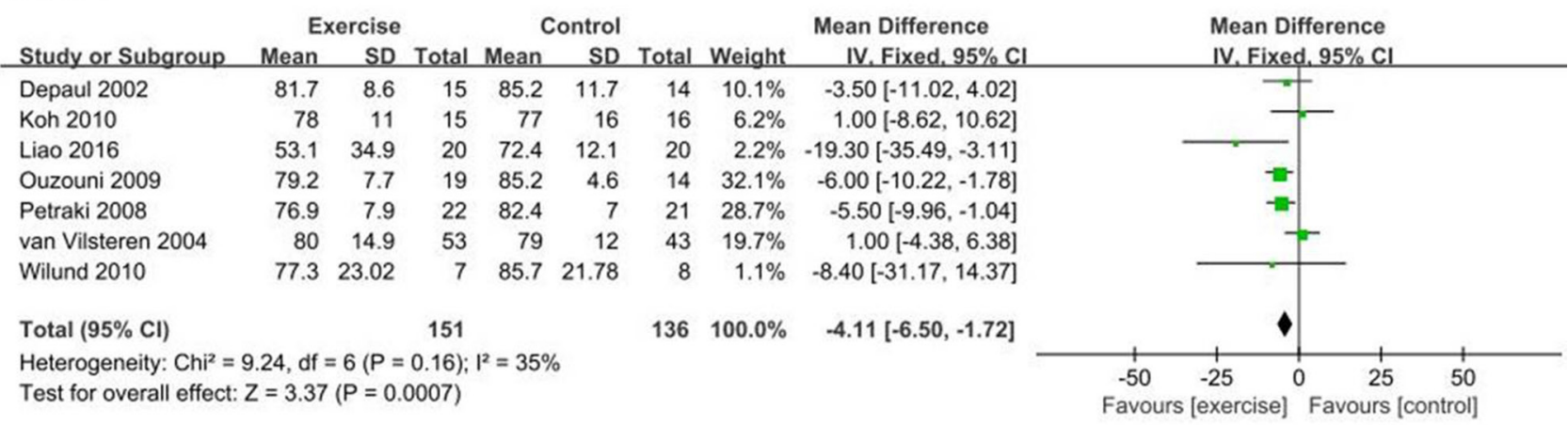

\section{(C)6MWD}

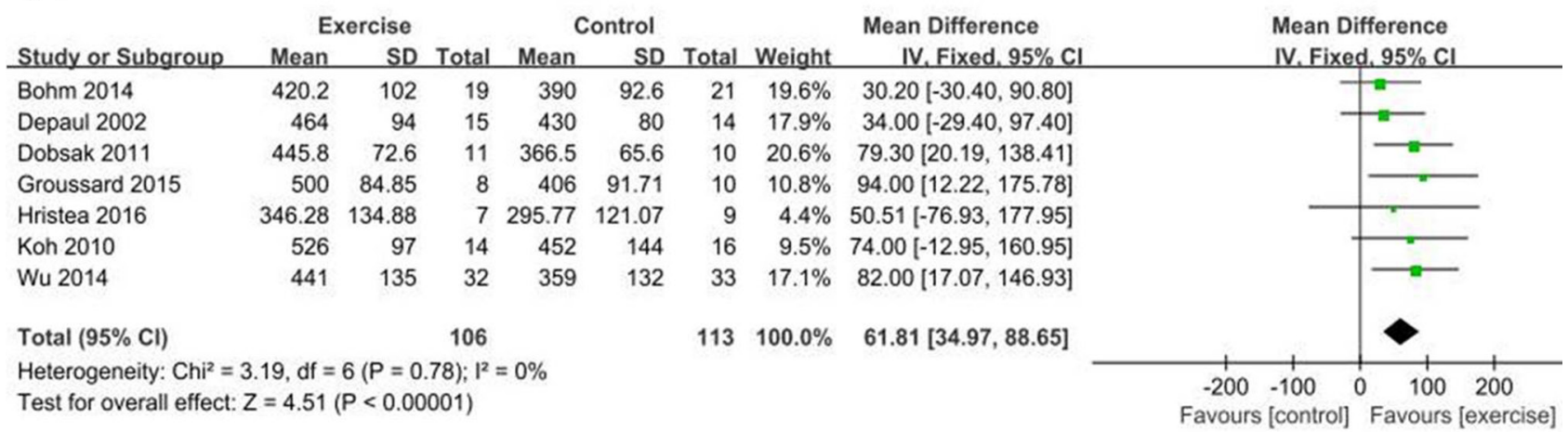

Figure 7 Forest plot: effect of intradialytic exercise on SBP, DBP and 6MWD. DBP, diastolic blood pressure; SBP, systolic blood pressure; 6MWD, 6 min walk distance.

which demonstrated that intradialytic exercise could improve physical performance (MD 61.81, 95\% CI 34.97 to 88.65 , $\mathrm{p}<0.0001$; figure $7 \mathrm{C}$ ).

\section{DISCUSSION}

This systematic review and meta-analysis provides positive evidence for the efficacy and safety of intradialytic exercise in MHD patients. The study included 27 RCTs involving 1215 subjects. Sixteen studies focused on aerobic exercise, four on resistance exercise and the remaining seven on a combination of aerobic and resistance exercises. The detailed exercise protocols varied among the studies.

Similar issues have been addressed by others before. Chung et al conducted a meta-analysis containing 17 RCTs with 651 patients. ${ }^{15}$ They found that intradialytic exercise could ameliorate depression, and improve quality of life, haemoglobin levels and $\mathrm{VO}_{2}$ peak among these patients; but failed to examine changes in $\mathrm{Kt} / \mathrm{V}$ and blood pressure. Sheng et $^{116} \mathrm{l}^{16}$ included 24 studies with 997 patients for meta-analysis and found that intradialytic exercise could improve $\mathrm{Kt} / \mathrm{V}, \mathrm{VO}_{2}$ peak, quality of life and blood pressure; but the results of physical performance (6MWD) and haemoglobin were contrary to Chung et al.

The results of this meta-analysis revealed that intradialytic exercise could improve Kt/V. This could be explained by the fact that exercise accelerated circulation and promoted the clearance of waste and excess water across the dialyser. Adequate dialysis is associated with reduced mortality. Held et $a \hat{l}^{8}$ found that mortality decreased by $7 \%$ with every 0.1 increase in $\mathrm{Kt} / \mathrm{V}$ when $\mathrm{Kt} / \mathrm{V}$ was below 1.3. Shinzato et $a l^{39}$ also found that when $\mathrm{Kt} / \mathrm{V}$ was lower than 1.8, the risk of all-cause death decreased with increases in $\mathrm{Kt} / \mathrm{V}$. A report by Charra $e t a t^{40}$ suggested that when $\mathrm{Kt} / \mathrm{V}$ reached 1.67, the 5-year survival rate would 
be $87 \%$, and the 20 -year survival rate would be $43 \%$. One haemodialysis study ${ }^{41}$ prospectively evaluated the impact of $\mathrm{Kt} / \mathrm{V}$ on patient life expectancy. Although there was no difference in patient life expectancy between different $\mathrm{Kt} / \mathrm{V}$ groups (1.25 vs 1.65), the beneficial effect of a higher dose of dialysis on survival was found in female patients in the subsequent subgroup analysis. Overall, higher $\mathrm{Kt} / \mathrm{V}$ is indicative of a better prognosis. Thus, it is probable that intradialytic exercise benefits patients on MHD by improving $\mathrm{Kt} / \mathrm{V}$ and increasing dialysis efficacy. However, the included RCTs did not conclude the effect of intradialytic exercise on survival rate.

Because cardiovascular complications and fatigue are common in patients with ESRD, patients on MHD usually have poor exercise capacity and are less physically active, which have been identified as independent risk factors of mortality. ${ }^{42}$ Indeed, better exercise capacity is related to lower risk of death. ${ }^{43}{ }^{44}$ Our study found that intradialytic exercise increased the $\mathrm{VO}_{2}$ peak. Generally speaking, the longer the duration of exercise, the more prominent improvement is expected in $\mathrm{VO}_{2}$ peak. There are reports suggesting that for every one MET increase in $\mathrm{VO}_{2}$ peak, there will be $12 \%$ and $17 \%$ decrease in the mortality of male $^{45}$ and female ${ }^{46}$ patients, respectively. Sietsema et $a t^{47}$ followed up 175 patients undergoing MHD and found that $\mathrm{VO}_{2}$ peak higher than $17.5 \mathrm{~mL} / \mathrm{kg} / \mathrm{min}$ was a significant predictor of survival. Consequently, we presume that intradialytic exercise may lower patient mortality through increasing $\mathrm{VO}_{2}$ peak. However, existing studies have not addressed this relationship yet. Notably, the $\mathrm{VO}_{2}$ peak measurement time points varied across the component studies, and these differences may result in clinical heterogeneity.

In terms of quality of life assessment, intradialytic exercise improved PCS levels, but not MCS levels. Depression is the most common mental disorder in the MHD population. ${ }^{48}$ Indeed, depression is more prevalent in the MHD population than the general population or even the chronic disease population, ${ }^{49}$ and unfortunately, depression increases the mortality of patients on MHD. ${ }^{50}$ We found that intradialytic exercise could improve depression severity. Unfortunately, there are few clinical trials (only four) focusing on the outcome of depression with a small sample size and diverse depression rating scales, such as Self-rating Depression Scale, Beck Depression Inventory, and the Hospital Anxiety and Depression Scale. This further increases the heterogeneity among studies. Confirmation of the association between intradialytic exercise and depression needs will require further investigation in high-quality randomised, controlled clinical trials.

Our study revealed a positive influence of intradialytic exercise on lowering blood pressure. Intradialytic exercise could reduce both SBP and DBP, without increasing the incidence of intradialytic hypotension. As a common complication, hypertension is closely related to increased cardiovascular events and mortality in MHD patients. A previous meta-analysis of five studies revealed that anti-hypertensive therapy might reduce all-cause mortality among the MHD population. ${ }^{52}$ Heerspink et al reported that the risk of cardiovascular disease reduced by $29 \%$, cardiovascular mortality reduced by $29 \%$ and all-cause mortality reduced by $20 \%$ when blood pressure was reduced by $4.5 / 2.3 \mathrm{~mm} \mathrm{Hg}{ }^{53}$

Adverse events were also evaluated to examine the safety of intradialytic exercise. The most common adverse events were hypotension and exercise-related injury. According to our results, only four patients suffered from limb pain and minor injury, and only one suffered from hypotension out of the total of 1215 cases analysed. It seemed that intradialytic exercise was unlikely to be associated with a high incidence of adverse events. Therefore, intradialytic exercise may be advantageous for patients undergoing MHD, with low associated risk. However, 12 of the trials reviewed did not report an incidence of adverse events, though under-reporting of exercise-related adverse events among MHD patients may be likely. Thus, to ensure patient safety, we recommend that implementation of intradialytic exercise be under the supervision of clinicians. In addition, our findings indicate that intradialytic exercise increases haemodialysis efficacy, alleviates depression and enhances exercise capacity among MHD patients. Furthermore, intradialytic exercise can lower blood pressure. However, we found no correlation between intradialytic exercise and albumin or $\mathrm{Hb}$ levels. Recently, a meta-analysis published by Young et $a l$ suggested that intradialytic exercise failed to improve $\mathrm{VO}_{2}$ and blood pressure; these findings were inconsistent with ours. ${ }^{54}$ This is possibly because our study enrolled studies involving aerobic exercise, resistance exercise or their combination; while the study by Young et al only included studies that were focused on aerobic exercise.

In this meta-analysis, we found that the method, the duration and the intensity of exercise differed between studies. Only a few studies examined the clinical influences of different exercise methods on the outcomes of patients. Afshar $e t a \hat{l}^{36}$ found that compared with resistance training, aerobic exercise effectively decreased serum creatinine and high-sensitivity $\mathrm{C}$ reactive protein. Segura-Ortí et a $\tilde{l}^{55}$ reported that resistance training did not differ from aerobic exercise in terms of their influences on physical performance. A study by Sheng $e t a l^{16}$ demonstrated that combining aerobic and resistance training could enhance the $\mathrm{VO}_{2}$ peak more efficiently than aerobic exercise alone, although significant $\mathrm{VO}_{2}$ peak elevation was only observed after the intradialytic exercise programme was implemented for more than 6 months. There is still a lack of evidence regarding the clinical impact of exercise intensity in terms of patient outcome. Due to the heterogeneity of exercise methods in the studies reviewed, we did not perform subgroup analyses. Further investigations are warranted to determine the optimal exercise method through which satisfactory outcomes can be achieved.

There are several limitations to this study. First, due to the short-term follow-up in the evaluated studies, the 
survival rate was not a typical endpoint for the included RCTs. Additionally, surrogate biomarkers can only reveal the benefit of intervention in a limited manner. Second, there was significant clinical heterogeneity in the exercise protocols (type, strength and duration of exercise), which might introduce bias to the results. Besides, the follow-up duration varied from 8 to 48 weeks. The variation in follow-up duration added to the interstudy clinical heterogeneity. Third, due to the heterogeneity of the exercise methods used in the included studies, we did not perform subgroup analyses. Thus, it is impossible for us to evaluate the effect of different types of exercise.

In conclusion, intradialytic exercise could improve $\mathrm{Kt} / \mathrm{V}$, exercise capacity, depression and quality of life as well as lower blood pressure among MHD patients. Intradialytic exercise might not increase the incidence of adverse events.

Contributors S0 and JP acted as guarantor for the validity of the study report. Study concept and design: JP and ZJ. Experiments were performed by: JP, ZJ, WW, LL and LZ. Analysis and interpretation of data: $L L, Y L$ and QL. Drafting of the manuscript: SO and JP. Critical revision of the manuscript for important intellectual content: SO.

Funding The authors have not declared a specific grant for this research from any funding agency in the public, commercial or not-for-profit sectors.

Competing interests None declared.

Patient consent for publication Not required.

Provenance and peer review Not commissioned; externally peer reviewed.

Data sharing statement № additional data are available.

Open access This is an open access article distributed in accordance with the Creative Commons Attribution Non Commercial (CC BY-NC 4.0) license, which permits others to distribute, remix, adapt, build upon this work non-commercially, and license their derivative works on different terms, provided the original work is properly cited, appropriate credit is given, any changes made indicated, and the use is non-commercial. See: http://creativecommons.org/licenses/by-nc/4.0/.

\section{REFERENCES}

1. Ortiz A, Covic A, Fliser D, et al. Epidemiology, contributors to, and clinical trials of mortality risk in chronic kidney failure. Lancet 2014;383:1831-43.

2. O'Hare AM, Tawney K, Bacchetti P, et al. Decreased survival among sedentary patients undergoing dialysis: results from the dialysis morbidity and mortality study wave 2. Am J Kidney Dis 2003;41:447-54.

3. Deschamps T. Let's programme exercise during haemodialysis (intradialytic exercise) into the care plan for patients, regardless of age. Br J Sports Med 2016;50:1357-8.

4. Parker K. Intradialytic Exercise is Medicine for Hemodialysis Patients. Curr Sports Med Rep 2016;15:269-75.

5. Maniam R, Subramanian P, Singh SK, et al. Preliminary study of an exercise programme for reducing fatigue and improving sleep among long-term haemodialysis patients. Singapore Med J 2014;55:476-82.

6. Kouidi E, Karagiannis V, Grekas D, et al. Depression, heart rate variability, and exercise training in dialysis patients. Eur J Cardiovasc Prev Rehabil 2010;17:160-7.

7. Dobsak P, Homolka P, Svojanovsky J, et al. Intra-dialytic electrostimulation of leg extensors may improve exercise tolerance and quality of life in hemodialyzed patients. Artif Organs 2012;36:71-8.

8. Hristea D, Deschamps T, Paris A, et al. Combining intra-dialytic exercise and nutritional supplementation in malnourished older haemodialysis patients: Towards better quality of life and autonomy. Nephrology 2016;21:785-90.

9. Ouzouni S, Kouidi E, Sioulis A, et al. Effects of intradialytic exercise training on health-related quality of life indices in haemodialysis patients. Clin Rehabil 2009;23:53-63.
10. Mohseni R, Emami Zeydi A, llali E, et al. The effect of intradialytic aerobic exercise on dialysis efficacy in hemodialysis patients: a randomized controlled trial. Oman Med J 2013;28:345-9.

11. Liao MT, Liu WC, Lin FH, et al. Intradialytic aerobic cycling exercise alleviates inflammation and improves endothelial progenitor cell count and bone density in hemodialysis patients. Medicine 2016;95:e4134

12. Konstantinidou E, Koukouvou G, Kouidi E, et al. Exercise training in patients with end-stage renal disease on hemodialysis: comparison of three rehabilitation programs. J Rehabil Med 2002;34:40-5.

13. Maravic M, Ostertag A, Urena $P$, et al. Dementia is a major risk factor for hip fractures in patients with chronic kidney disease. Osteoporos Int 2016;27:1665-9.

14. March DS, Graham-Brown MP, Young HM, et al. 'There is nothing more deceptive than an obvious fact': more evidence for the prescription of exercise during haemodialysis (intradialytic exercise) is still required. Br J Sports Med 2017;51:1379.

15. Chung YC, Yeh ML, Liu YM. Effects of intradialytic exercise on the physical function, depression and quality of life for haemodialysis patients: a systematic review and meta-analysis of randomised controlled trials. J Clin Nurs 2017;26:1801-13.

16. Sheng $\mathrm{K}$, Zhang $\mathrm{P}$, Chen $\mathrm{L}$, et al. Intradialytic exercise in hemodialysis patients: a systematic review and meta-analysis. Am J Nephrol 2014:40:478-90.

17. Jadad AR, Moore RA, Carroll D, et al. Assessing the quality of reports of randomized clinical trials: is blinding necessary? Control Clin Trials 1996;17:1-12.

18. Makhlough A, Ilali E, Mohseni R, et al. Effect of intradialytic aerobic exercise on serum electrolytes levels in hemodialysis patients. Iran $\mathrm{J}$ Kidney Dis 2012;6:119-23.

19. Johansen KL, Painter PL, Sakkas GK, et al. Effects of resistance exercise training and nandrolone decanoate on body composition and muscle function among patients who receive hemodialysis: A randomized, controlled trial. J Am Soc Nephrol 2006;17:2307-14.

20. van Vilsteren MC, de Greef MH, Huisman RM. The effects of a low to-moderate intensity pre-conditioning exercise programme linked with exercise counselling for sedentary haemodialysis patients in The Netherlands: results of a randomized clinical trial. Nephrol Dial Transplant 2005;20:141-6.

21. Reboredo MM, Pinheiro BV, Neder JA, et al. Effects of aerobic training during hemodialysis on heart rate variability and left ventricular function in end-stage renal disease patients. J Bras Nefrol 2010;32:367-73.

22. Chen JL, Godfrey S, Ng TT, Tt N, et al. Effect of intra-dialytic, low-intensity strength training on functional capacity in adult haemodialysis patients: a randomized pilot trial. Nephrol Dial Transplant 2010;25:1936-43.

23. Koh KP, Fassett RG, Sharman JE, et al. Effect of intradialytic versus home-based aerobic exercise training on physical function and vascular parameters in hemodialysis patients: a randomized pilot study. Am J Kidney Dis 2010;55:88-99.

24. Painter P, Moore G, Carlson L, et al. Effects of exercise training plus normalization of hematocrit on exercise capacity and health-related quality of life. Am J Kidney Dis 2002;39:257-65.

25. Wilund KR, Tomayko EJ, Wu PT, Pt W, et al. Intradialytic exercise training reduces oxidative stress and epicardial fat: a pilot study. Nephrol Dial Transplant 2010;25:2695-701.

26. Song WJ, Sohng KY. Effects of progressive resistance training on body composition, physical fitness and quality of life of patients on hemodialysis. J Korean Acad Nurs 2012;42:947-56.

27. Kouidi EJ, Grekas DM, Deligiannis AP. Effects of exercise training on noninvasive cardiac measures in patients undergoing longterm hemodialysis: a randomized controlled trial. Am J Kidney Dis 2009:54:511-21.

28. DePaul V, Moreland J, Eager T, et al. The effectiveness of aerobic and muscle strength training in patients receiving hemodialysis and EPO: a randomized controlled trial. Am J Kidney Dis 2002;40:1219-29.

29. Giannaki CD, Sakkas GK, Karatzaferi C, et al. Effect of exercise training and dopamine agonists in patients with uremic restless legs syndrome: a six-month randomized, partially double-blind, placebocontrolled comparative study. BMC Nephrol 2013;14:194.

30. Bohm C, Stewart K, Onyskie-Marcus J, et al. Effects of intradialytic cycling compared with pedometry on physical function in chronic outpatient hemodialysis: a prospective randomized trial. Nephrol Dial Transplant 2014;29:1947-55.

31. Wu Y, He Q, Yin X, et al. Effect of individualized exercise during maintenance haemodialysis on exercise capacity and healthrelated quality of life in patients with uraemia. J Int Med Res 2014:42:718-27. 
32. Groussard C, Rouchon-Isnard M, Coutard C, et al. Beneficial effects of an intradialytic cycling training program in patients with end-stage kidney disease. Appl Physiol Nutr Metab 2015;40:550-6.

33. Petraki M, Kouidi E, Grekas D, et al. Effects of exercise training during hemodialysis on cardiac baroreflex sensitivity. Clin Nephrol 2008;70:210-9.

34. Parsons TL, Toffelmire EB, King-VanVlack CE. The effect of an exercise program during hemodialysis on dialysis efficacy, blood pressure and quality of life in end-stage renal disease (ESRD) patients. Clin Nephrol 2004;61:261-74.

35. Martin-Alemañy G, Valdez-Ortiz R, Olvera-Soto G, et al. The effects of resistance exercise and oral nutritional supplementation during hemodialysis on indicators of nutritional status and quality of life. Nephrol Dial Transplant 2016;31:1712-20.

36. Afshar R, Shegarfy L, Shavandi N, et al. Effects of aerobic exercise and resistance training on lipid profiles and inflammation status in patients on maintenance hemodialysis. Indian $\mathrm{J}$ Nephrol 2010;20:185-9.

37. de Lima MC, Cicotoste CL, Cardoso KS, et al. Effect of exercise performed during hemodialysis: strength versus aerobic. Ren Fail 2013;35:697-704.

38. Held PJ, Port FK, Wolfe RA, et al. The dose of hemodialysis and patient mortality. Kidney Int 1996;50:550-6.

39. Shinzato T, Nakai S, Akiba T, et al. Survival in long-term haemodialysis patients: results from the annual survey of the Japanese Society for Dialysis Therapy. Nephrol Dial Transplant 1997;12:884-8.

40. Charra B, Calemard E, Ruffet M, et al. Survival as an index of adequacy of dialysis. Kidney Int 1992;41:1286-91.

41. Eknoyan G, Beck GJ, Cheung AK, et al. Effect of dialysis dose and membrane flux in maintenance hemodialysis. N Engl J Med 2002;347:2010-9.

42. Johansen KL, Chertow GM, Jin C, et al. Significance of frailty among dialysis patients. J Am Soc Nephrol 2007;18:2960-7.

43. Stack AG, Molony DA, Rives T, et al. Association of physical activity with mortality in the US dialysis population. Am J Kidney Dis 2005;45:690-701.

44. Johansen KL. Physical functioning and exercise capacity in patients on dialysis. Adv Ren Replace Ther 1999;6:141-8.
45. Myers J, Prakash M, Froelicher V, et al. Exercise capacity and mortality among men referred for exercise testing. $N$ Engl $\mathrm{J}$ Med 2002;346:793-801.

46. Gulati M, Pandey DK, Arnsdorf MF, et al. Exercise capacity and the risk of death in women: the St James Women Take Heart Project. Circulation 2003;108:1554-9.

47. Sietsema KE, Amato A, Adler SG, et al. Exercise capacity as a predictor of survival among ambulatory patients with end-stage renal disease. Kidney Int 2004;65:719-24.

48. Ćwiek A, Czok M, Kurczab B, et al. Association between depression and hemodialysis in patients with chronic kidney disease. Psychiatr Danub 2017;29:499-503.

49. Klarić M, Letica I, Petrov B, et al. Depression and anxiety in patients on chronic hemodialysis in University Clinical Hospital Mostar. Coll Antropol 2009;33(Suppl 2):153-8.

50. Khalil AA, Lennie TA, Frazier SK. Understanding the negative effects of depressive symptoms in patients with ESRD receiving hemodialysis. Nephrol Nurs J 2010;37:289-95.

51. Hung KC, Wu CC, Chen HS, et al. Serum IL-6, albumin and comorbidities are closely correlated with symptoms of depression in patients on maintenance haemodialysis. Nephrol Dial Transplant 2011;26:658-64.

52. Agarwal R, Sinha AD. Cardiovascular protection with antihypertensive drugs in dialysis patients: systematic review and meta-analysis. Hypertension 2009;53:860-6.

53. Heerspink HJ, Ninomiya T, Zoungas S, et al. Effect of lowering blood pressure on cardiovascular events and mortality in patients on dialysis: a systematic review and meta-analysis of randomised controlled trials. Lancet 2009;373:1009-15.

54. Young HML, March DS, Graham-Brown MPM, et al. Effects of intradialytic cycling exercise on exercise capacity, quality of life, physical function and cardiovascular measures in adult haemodialysis patients: a systematic review and meta-analysis. Nephrol Dial Transplant 2018;33:1436-45.

55. Segura-Ortí E, Kouidi E, Lisón JF. Effect of resistance exercise during hemodialysis on physical function and quality of life: randomized controlled trial. Clin Nephrol 2009;71:527-37. 